\title{
An audit of primary medical conditions in children admitted to the paediatric intensive care unit of Charlotte Maxeke Johannesburg Academic Hospital
}

\author{
R K Mopeli, MB BCh, FCPaed (SA); D E Ballot, MB ChB, FCPaed (SA), PhD; \\ D A White, MB BCh, FCPaed (SA), MMed (Paed), Dip Allerg (SA), Cert Pulm (SA) Paed \\ Department of Paediatrics, Faculty of Health Sciences, University of the Witwatersrand, Johannesburg, South Africa
}

Corresponding author: R K Mopeli (kmopeli@yahoo.com)

\begin{abstract}
Background. There is approximately one paediatric intensive care unit (PICU) bed per 22800 children in SA, making PICU beds a very limited resource.

Objectives. To determine the spectrum of medical conditions in children admitted to a PICU, their outcomes, and to compare the number and outcomes of HIV-exposed/infected children v. HIV-unexposed children.

Methods. This was a retrospective chart review of children older than 28 days, admitted to Charlotte Maxeke Johannesburg Academic Hospital (CMJAH) PICU for medical conditions from 1 January 2013 to 31 July 2014.

Results. There were 883 admissions; 518 (59\%) were neonates and 234 (26.5\%) were surgical patients, leaving a final sample of 131 (14.8\%) children with medical conditions. The median age of children admitted was 3.8 months. Out of 131 children, 44 (34\%) were HIV-exposed and $16(12.2 \%)$ had a positive HIV polymerase chain reaction (PCR) result. Lower respiratory tract infections (LRTIs) accounted for two-thirds of all admissions at $84(64.1 \%)$ and were significantly more common in HIV-exposed children $(p=0.0005) ; 32(24.4 \%)$ patients died. HIV-exposed children stayed 3 days longer $(p=0.015)$, were ventilated for 4 more days $(p=0.012)$ and were three times more likely to require high-frequency oscillatory ventilation $(p=0.0005)$ than HIV-unexposed children. Mortality was similar between these two groups. Children confirmed HIV PCR-positive had a significantly longer duration of ICU stay $(p=0.03)$ and ventilation $(p=0.006)$ than those who were exposed but uninfected.

Conclusion. There were 883 children admitted in 19 months to CMJAH PICU. A total of $15 \%$ of admissions were for medical conditions, two-thirds of which were for LRTIs. One-third of the children were HIV-exposed and had similar outcomes to their unaffected counterparts, although their duration of ventilation and length of stay were longer.
\end{abstract}

S Afr J Child Health 2016;10(4):221-226. DOI:10.7196/SAJCH.2016.v10i4.1187

South Africa (SA) is a low- to middle-income country with an estimated population of 18.6 million children. ${ }^{[1]}$ The mortality rate in $<5$-year-olds was estimated to be 41 per 1000 live births in 2015, with lower respiratory tract infections (LRTIs) causing $16.9 \%$ of those deaths. ${ }^{[2]}$ Many of these children may have benefitted from admission into a paediatric intensive care unit (PICU) where mechanical ventilation could have been offered to them. However, there are not enough PICU beds in SA to cater for the needs of the most seriously ill children.

An SA national audit of critical care resources done in 2005 found that only 815 of 4618 ICU beds were assigned to paediatric and neonatal patients, and these are often shared. There is a paucity of data on the breakdown of allocated paediatric v. neonatal beds. Most hospitals were found to be admitting children to combined medical and surgical units. ${ }^{[3]}$ There is therefore approximately one paediatric ICU bed per 22800 (815/18.6 million) children.

In this SA setting with limited resources, decisions have to be made as to how best to allocate these resources. Some PICUs have developed and implemented explicit policies for the use of PICU resources, thus providing a 'reasonable' process for equitable utilisation of limited resources; however, SA does not have national or provincial guidelines for admitting patients to an ICU..$^{[4,5]}$

Various scoring systems have been developed to allow for assessment of the quality of care in PICUs, e.g. PRISM III, PIM2, PEMOD, PELOD, TISS and SOFA scores. ${ }^{[6]}$ Wells et al. ${ }^{[7]}$ found the PRISM score to have a poor discriminatory function over a 6-year period (1989 - 1994) in a SA ICU. Subsequent to that a study done at the Red Cross War Memorial Children's Hospital in 2007 found that the PIM and PIM2 scores demonstrated good overall discrimination, therefore validating their use in SA ${ }^{[8]}$ Data on admission trends and outcomes in SA PICUs, which could be used to develop our own scoring systems, are scarce.

Charlotte Maxeke Johannesburg Academic Hospital (CMJAH) is a tertiary teaching and referral centre that provides healthcare services to the people of Gauteng Province, SA, as well as to neighbouring provinces. The 220-bed paediatric service caters for all paediatric medical and paediatric surgical subspecialties. There are 15 beds in the PICU, which are in high demand. The consultant staff in the PICU consist of four neonatologists and one paediatric pulmonologist. There are no dedicated paediatric intensivists. A retrospective review was done from 1993 to 1994 by Ballot et al. ${ }^{\left[{ }^{[9]}\right.}$ which included all patients $>3$ months of age admitted to the PICU. They found that patients with the highest mortality rates were those with complicated infectious illnesses, near-drowning, gastroenteritis and cardiomyopathy. An audit of this nature at CMJAH PICU has not been done for several years.

\section{Impact of HIV on PICU admissions}

SA is faced with one of the highest rates of HIV infection worldwide. The Joint United Nations Programme on HIV/AIDS estimated that in 2013 there were 360000 children from 0 to 14 years of age living with HIV in SA. ${ }^{[10]}$ In the era before highly active antiretroviral therapy (HAART), HIV-infected children with co-infections such as Pneumocystis jirovecii pneumonia (PCP) had worse outcomes than other patients admitted to PICU and were therefore not routinely ventilated. Admitting HIV-infected children with severe pneumonia 
to a PICU in a setting of scarce resources created several ethical dilemmas for paediatricians. ${ }^{[1]}$ Often, the first suspicion of HIV in infected children is after they have been admitted to the PICU. ${ }^{[12]}$

More information is needed as to whether there are differences in comorbidities and outcomes of HIV-exposed and HIV-infected children admitted to PICU and if these differences should be considered when making decisions for PICU bed allocations. A retrospective chart review by Rabie et al. ${ }^{[5]}$ at Tygerberg Children's Hospital, to determine the prevalence and outcome of HIV-infected patients in PICU, showed a median length of stay for HIV-infected children of 6 days, which was significantly longer than for the non HIV-infected children ( 3 days), $p=0.0001$ ). Cost differentials for HIV-infected and HIV-uninfected children admitted for the management of pneumonia in a public setting were determined by Kitchin et al. ${ }^{[13]}$ who found that the length of stay for HIVinfected children was 5.7 days longer among admissions to the PICU, and that the cost of admission for HIV-infected children was significantly higher. They also found that the number of deaths of HIV-infected children were $28.1 \%$ higher than uninfected children. However, it has been shown that early initiation of antiretroviral (ARV) therapy can improve outcomes of HIV-infected children in a PICU. ${ }^{[11]}$

Acute respiratory failure as a result of LRTI is a major cause for admission in HIV-exposed and HIV-infected children. Rabie et $a l .{ }^{[5]}$ found that $76 \%$ of HIV-infected children admitted to the PICU were admitted for acute respiratory failure and 33\% of admissions had a confirmed diagnosis of PCP. Another review found that cytomegalovirus (CMV) infection had affected nearly $90 \%$ of HIVexposed children. ${ }^{[14]}$

\section{Objectives}

To describe the disease spectrum and outcome of children admitted for medical conditions to PICU at CMJAH, and to determine the spectrum of medical conditions among children admitted to the PICU, the short-term outcomes of children admitted to the PICU and the number and outcomes of HIV-exposed or HIV-infected children admitted compared with HIV-unexposed children.

\section{Methods}

This study was a retrospective review conducted in the PICU of CMJAH, a referral hospital in Gauteng, SA. The records of children admitted to the PICU from 1 January 2013 to 31 July 2014 were reviewed. Admission to the PICU at the time of the study was primarily based on the need for ventilation, but occasionally patients requiring intensive observation were admitted. The study included children $>28$ days old admitted to PICU for medical conditions. All surgical and trauma ad-missions were excluded. If a child had had a medical condition but subsequently required surgery, they were excluded. Children with a confirmed HIV infection would not be routinely readmitted to the PICU. The records were reviewed for demographics, admission diagnosis, HIV status, duration of ICU stay and ventilation, and survival to discharge from the PICU. Some children had multiple diagnoses; each one was counted.

The definitions used for the conditions have been listed in Table 1. All children admitted with a medical condition were routinely tested for HIV with an enzyme-linked immunosorbent assay test. Blood specimens were taken under sterile conditions for bacterial culture in all patients. Children with acute LRTIs were only screened for respiratory pathogens if clinically indicated, at the discretion of the attending physician, including any of the following: tracheal aspirates for multiplex real-time reverse transcription polymerase chain reaction (RT-PCR) assay for respiratory viruses, microscopy and culture, pertussis PCR, gene Xpert for tuberculosis and/or Pneumocystis carinii pneumonia (PCP) immunofluorescence. Children were managed according to standard treatment protocols

at the discretion of the attending physician. Empirical antibiotics for bacterial pneumonia were intravenous ampicillin and gentamicin. Children with suspected PCP and cytomegalovirus (CMV) pneumonia were treated as a syndrome as the two are not easy to differentiate clinically; therefore, children were treated empirically with trimethoprim-sulphamethoxazole plus corticosteroids and ganciclovir, while awaiting confirmatory results.

After reviewing the records for conditions and outcomes, the children were then divided into two groups: HIV-exposed and HIVunexposed. Comparisons were made between the two groups to find statistically significant differences in all the variables. The group of HIV-exposed children was further divided into those who were HIV PCR-positive and those who were HIV PCR-negative. These two groups were also compared for any significant differences.

Data were managed using Research Electronic Data Capture tools (REDCap) (Vanderbilt University, USA), hosted by the University of the Witwatersrand. ${ }^{[15]}$ Information was captured for each patient on discharge from the PICU. De-identified data were then entered into Microsoft Excel (USA). Cases were allocated a study number.

\section{Statistical analysis}

Categorical variables were described using percentages and frequencies. Continuous variables were described using median and range as the data were skewed. Comparisons were made using the $\chi^{2}$ test for categorical variables and the Mann-Whitney U-test for continuous variables. A $p$-value $<0.05$ was used as the level of significance.

\section{Ethical considerations}

Ethical approval was obtained from the University of the Witwatersrand Human Research Ethics Committee (Ethics Clearance no.: M140363). Permission to review the patients' records

\section{Table 1. Definitions}

\begin{tabular}{|c|c|}
\hline Medical condition & $\begin{array}{l}\text { A life-threatening disease not } \\
\text { requiring surgical intervention }\end{array}$ \\
\hline Duration & $\begin{array}{l}\text { Period of time calculated in } \\
\text { days and not hours }\end{array}$ \\
\hline $\begin{array}{l}\text { Upper respiratory tract } \\
\text { infections (URTIs) }\end{array}$ & $\begin{array}{l}\text { An infection affecting the } \\
\text { respiratory tract above the level } \\
\text { of the larynx, including croup } \\
\text { and retropharyngeal abscess }\end{array}$ \\
\hline LRTI & $\begin{array}{l}\text { An infection affecting the } \\
\text { respiratory tract from below } \\
\text { the larynx, leading to cough, } \\
\text { difficulty breathing, tachypnoea } \\
\text { or chest wall indrawing }\end{array}$ \\
\hline Clinical diagnosis of PCP & $\begin{array}{l}\text { An LRTI accompanied by } \\
\text { severe hypoxia, a clear chest on } \\
\text { auscultation and a ground-glass } \\
\text { interstitial infiltrate on chest } \\
\text { radiograph findings }\end{array}$ \\
\hline Neonates & $\begin{array}{l}\text { Children }<28 \text { days old, } \\
\text { including those who had been } \\
\text { discharged and admitted from } \\
\text { home }\end{array}$ \\
\hline Bacterial infection & $\begin{array}{l}\text { Diagnosis made on the basis of } \\
\text { a positive blood culture }\end{array}$ \\
\hline Cardiovascular conditions & $\begin{array}{l}\text { Includes congenital cardiac } \\
\text { lesions, myocarditis, shock, } \\
\text { cardiac failure and arrhythmia }\end{array}$ \\
\hline
\end{tabular}


was obtained from the clinical manager of CMJAH.

\section{Results \\ Demographics}

There were 883 PICU admissions during the 19-month study period. Of these, 518 (59\%) were neonates and $234(26.5 \%)$ were surgical patients. The remaining sample therefore included 131 children (14.8\%). The male:female ratio was 1:0.66. The median age of the patients admitted was 3.8 months with an interquartile range (IQR) of 14.3 months.

The median (IQR) duration of ventilation was 4 (6) days, while the duration of stay was 5 (7) days. There were $32 / 131(24.4 \%)$ deaths in the PICU, and a further 8 (6\%) children died in the hospital wards after discharge from the PICU.

There were 129/131 children tested for HIV. Of these, 44/131 (33.5\%) were HIVexposed, 85/131 (65.9\%) were unexposed, and HIV exposure was unknown for 2 . The 2 children whose status was unknown were excluded from further analysis. Of the 131 children, 16 (12.2\%) were HIV-infected with a positive HIV PCR.

\section{Conditions of children admitted}

The spectrum of medical conditions was wide, with 84/131 (64.1\%) having LRTIs, accounting for the majority of admissions (Fig. 1).

Of the 131 children, 122 were intubated and ventilated, 1 received continuous positive airway pressure, and 8 were not ventilated. Of those 122 who were on intermittent positive pressure ventilation (IPPV), 14 (11.4\%) were switched to high-frequency oscillatory ventilation (HFOV). Inotropic support was needed by 12 children.

\section{Pathogens}

There were 22/131 (16.7\%) positive bacterial cultures on blood specimens from the children. Coagulase-negative Staphylococcus was the bacterial pathogen most frequently identified, in 6/131 (4.6\%) children (Table 2).

Viral pathogens were identified in 16/131 (12.2\%) children. No fungi were isolated, and PCP was identified in only $3 / 131 \quad(2.3 \%)$ tracheal aspirates by direct immunofluorescence assay (Tables 2 and 3). Eight children had a clinical diagnosis of CMV made by the admitting doctors. These 8 patients were also found to be HIV-positive on DNA PCR. The patients had their CMV viral loads quantified from a blood specimen by DNA PCR to support the diagnosis, and were empirically treated with ganciclovir while awaiting viral load results. Only 2 patients had viral loads $>6000 \mathrm{IU} / \mathrm{mL}$, while 5 were below the level of quantification and 1 was indeterminate. At the CMJAH PICU a viral load of greater than 4.0 log copies is considered indicative of active CMV

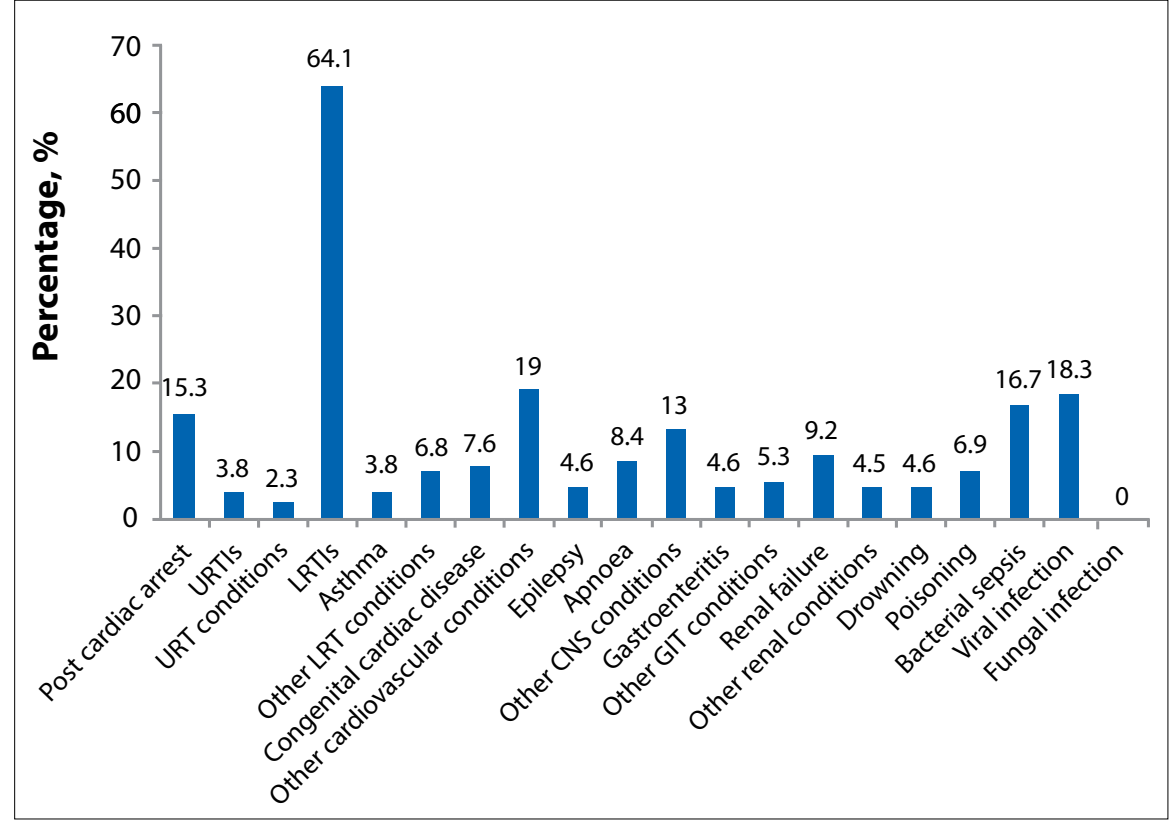

Fig. 1. Admission diagnoses for children admitted with medical conditions to the PICU from 1 January 2013 to 31 July 2014. Some children had multiple admission diagnoses.

Table 2. Infections of children admitted confirmed on blood culture

\begin{tabular}{ll}
\hline Infections & $n(\%)$ \\
\hline Bacterial sepsis & $22 / 131(16.7)$ \\
Klebsiella pneumoniae & $1(0.8)$ \\
ESBL Klebsiella & $2(1.5)$ \\
Staphylococcus aureus & $1(0.8)$ \\
Coagulase-negative Staphylococcus & $6(4.6)$ \\
Streptococcus viridans & $4(3.1)$ \\
Streptococcus pneumoniae & $1(0.8)$ \\
Acinetobacter baumannii & $1(0.8)$ \\
Escherichia coli & $5(3.8)$ \\
Enterococcus faecalis & $2(1.5)$ \\
Enterobacter cloacae & $1(0.8)$
\end{tabular}

infection and disease, and infection was therefore not proven in the eight children.

\section{Comparison between HIV- unexposed and HIV-exposed children}

Table 4 compares the demographics, medical conditions and outcomes of HIV-exposed and unexposed children. A total of 44/131 (34.1\%) were HIV-exposed. The median duration of stay for HIV-exposed children of 8 days was significantly longer than the 5 days for HIV-unexposed children $(p=0.015)$. Duration of ventilation was also 4 days longer for HIV-exposed children $(p=0.012)$. More HIV-exposed children $(11 / 44(25 \%))$ transitioned to HFOV than HIV-unexposed children (3/85 (3.5\%), $p=0.0005)$.
LRTIs accounted for more than half of all admissions, regardless of HIV status, but HIV-exposed children were much more likely to be admitted with LRTI (90.9\%) than HIVunexposed children (51.8\%) $(p=0.0005)$. There was no significant difference in the number of deaths between the two groups.

Some of the diagnoses of bacterial or viral pneumonia were made clinically by the admitting doctor before blood or tracheal aspirate samples could be collected, and the children were therefore treated empirically for those conditions. Taking a closer look at the LRTIs it was found that HIV-exposed children were significantly more likely to present with bacterial pneumonia (45.5\%) compared with HIV-unexposed children (20.3\%) $(p=0.002)$. All 10 children who had a clinical diagnosis of PCP were HIV-exposed ( $p=0.0005)$. Eight 
of these children had $\beta$-D glucan assays done. Five children had a $\beta-\mathrm{D}$ glucan level greater than $500 \mathrm{pg} / \mathrm{mL}$, and the others were below that level. This supports but does not confirm the diagnosis made by the doctors clinically.

Table 3. Infections of children admitted confirmed on tracheal aspirate

\begin{tabular}{ll}
\hline Infections & $\boldsymbol{n}(\%)$ \\
\hline Viral infection & $16 / 131(12.2)$ \\
Adenovirus & $4(3.1)$ \\
$\begin{array}{l}\text { Respiratory syncytial } \\
\text { virus (RSV) }\end{array}$ & $9(6.9)$ \\
Other viruses & $3(2.3)$ \\
P. jirovecii & $3(2.3)$ \\
Fungal infection & $0(0)$
\end{tabular}

\section{Comparison of HIV PCR-positive and PCR-negative children}

Of the 44 children who were HIV-exposed, 1 child did not undergo a PCR test. A total of $16 / 43(37.2 \%)$ children were found to be HIV PCR-positive. The mortality between the groups was not significantly different. Of significance was that HIV PCR-positive children required more days of ventilation $(p=0.006)$, were more likely to require HFOV ( $p=0.0005)$ and stayed longer in PICU $(p=0.03)$ than HIV-exposed PCR-negative children (Table 5).

There were no significant differences with regard to the number and type of medical conditions found.

\section{Discussion}

This audit showed that the majority of admissions to the PICU at CMJAH are

Table 4. Comparison of HIV-unexposed children with HIV-exposed children

\begin{tabular}{|c|c|c|c|}
\hline & $\begin{array}{l}\text { HIV-unexposed, } \\
n(\%)^{\star}\end{array}$ & $\begin{array}{l}\text { HIV-exposed, } \\
n(\%)^{\star}\end{array}$ & $p$-value \\
\hline Total admissions (2 unknown) & $85(65.9)$ & $44(34.1)$ & - \\
\hline Age (months), median & 6.3 & 2.7 & 0.0005 \\
\hline Died in the PICU & $19(22.4)$ & $11(25)$ & 0.730 \\
\hline PICU stay (days), median & 5 & 8 & 0.015 \\
\hline Duration ventilated (days), median & 4 & 8 & 0.012 \\
\hline Readmission & $11(12.9)$ & 0 & 0.013 \\
\hline IPPV & $77(90.6)$ & $42(95.5)$ & 0.320 \\
\hline HFOV & $3(3.5)$ & $11(25.0)$ & 0.0005 \\
\hline Inotropes & $6(7.1)$ & $5(11.4)$ & 0.400 \\
\hline \multicolumn{4}{|l|}{ Respiratory tract conditions } \\
\hline \multicolumn{4}{|c|}{ Upper respiratory tract (URT) conditions } \\
\hline URTIs & $4(4.7)$ & $1(2.3)$ & 0.394 \\
\hline Other URT conditions & $1(1.2)$ & $2(4.5)$ & 0.210 \\
\hline LRT infections & $44(51.8)$ & $40(90.9)$ & 0.0005 \\
\hline Asthma & $5(5.9)$ & 0 & 0.100 \\
\hline Pleural effusion & $2(2.4)$ & 0 & 0.300 \\
\hline Other LRT conditions & $4(4.7)$ & 0 & 0.250 \\
\hline \multicolumn{4}{|l|}{ Other systems } \\
\hline Cardiovascular conditions & $25(29.4)$ & $9(20.5)$ & 0.270 \\
\hline $\begin{array}{l}\text { Central nervous system (CNS) } \\
\text { conditions }\end{array}$ & $23(27.1)$ & $9(20.5)$ & 0.410 \\
\hline $\begin{array}{l}\text { Gastrointestinal tract (GIT) } \\
\text { conditions }\end{array}$ & $9(10.6)$ & $3(6.8)$ & 0.485 \\
\hline Renal conditions & $16(18.8)$ & $2(4.5)$ & 0.027 \\
\hline \multicolumn{4}{|l|}{ Infections } \\
\hline Bacterial sepsis & $12(14.1)$ & $10(22.7)$ & 0.218 \\
\hline Viral infections & $10(11.8)$ & $6(13.6)$ & 0.780 \\
\hline RSV & $5(5.9)$ & $4(9.1)$ & 0.490 \\
\hline PCP infection & $1(1.2)$ & $2(4.5)$ & 0.229 \\
\hline
\end{tabular}

neonates, followed by post-surgical and trauma patients. Medical admissions comprised $15 \%$ of the total, with the majority being infants of $\leq 3.7$ months of age. More male than female children were admitted, which was a similar finding to other studies. ${ }^{[16]}$ There were $34.1 \%$ HIV-exposed children, while $12.2 \%$ were HIV PCR-positive. We were unable to calculate how many children were denied beds owing to their positive HIV status, as this information was unavailable. It's possible that there may have been a selection bias. All the children admitted were severely ill, as $92 \%$ required conventional ventilation and $10 \%$ requiring transition to HFOV.

The median duration of stay was 5 days, and $24.4 \%$ of children died in the PICU. The spectrum of conditions was wide, but the predominance of acute LRTI was not surprising, as up to $40 \%$ of hospital admissions in SA are accounted for by communityacquired pneumonia. ${ }^{[17]}$ Respiratory viral pathogens were identified in $12.2 \%$ of admissions, with RSV accounting for the highest number. RSV is known to be the most common cause of moderate or severe bronchiolitis. ${ }^{[18]}$

Only three children had confirmed PCP infection on tracheal aspirate analysis. Two of the 3 were HIV-exposed and 1 was HIVunexposed. PCP has been found in HIVunexposed children who have compromised immune systems for other reasons such as malnutrition.

\section{Comparison between HIV-exposed and HIV-unexposed children}

There was no significant difference in mortality rates between HIV-exposed and HIV-unexposed patients. This is possibly because of the ventilation strategies and choice of antibiotics used in the PICU. HIVexposed children stayed 3 days longer in the PICU and were ventilated for 4 more days than HIV-unexposed children. Length of stay may be linked to increased expense.

In the CMJAH PICU, HFOV is used as a second-line ventilation strategy for children who remain in respiratory fail-ure, or whose condition deteriorates on conventional mechanical ventilation. A total of $25 \%$ of HIV-exposed children were converted to HFOV compared with only $3.5 \%$ of unexposed children $(p=0.0005)$. This is another indicator that HIV-exposed children were generally more seriously ill and required more support.

Almost all HIV-exposed children suffered from a LRTI. A birth cohort study done in Paarl, SA, showed that exposure to HIV was a significant independent risk factor for severe pneumonia. This could be because of limited protection owing to lower maternal antibodies. $^{[19]}$ 
Table 5. Comparison of HIV PCR-negative and HIV PCR-positive children

\begin{tabular}{|c|c|c|c|}
\hline & $\begin{array}{l}\text { HIV PCR- } \\
\text { negative, } n(\%)^{*}\end{array}$ & $\begin{array}{l}\text { HIV PCR- } \\
\text { positive, } n(\%)^{*}\end{array}$ & $p$-value \\
\hline Total admissions & $27(62.7)$ & $16(37.2)$ & - \\
\hline Age (months), median (IQR) & $2.5(1.9)$ & $3.1(1.2)$ & 0.030 \\
\hline Died in the PICU & $5(18.5)$ & $5(31.3)$ & 0.330 \\
\hline PICU stay (days), median & 5 & 11.5 & 0.030 \\
\hline Time ventilated (days), median & 4 & 11 & 0.006 \\
\hline IPPV & $26(96.3)$ & $15(93.8)$ & - \\
\hline HFOV & $2(7.4)$ & $9(56.3)$ & 0.0005 \\
\hline Inotropes & $2(7.4)$ & $2(12.5)$ & 0.580 \\
\hline \multicolumn{4}{|l|}{ Respiratory tract conditions } \\
\hline \multicolumn{4}{|l|}{ URT conditions } \\
\hline URTIs & $1(3.7)$ & 0 & - \\
\hline Other URT conditions & $1(3.7)$ & $1(6.3)$ & - \\
\hline \multicolumn{4}{|l|}{ LRT conditions } \\
\hline LRT infections & $23(85.2)$ & $16(100)$ & 0.100 \\
\hline PCP & $3(11.1)$ & $7(43.8)$ & 0.140 \\
\hline \multicolumn{4}{|l|}{ Other systems } \\
\hline Cardiovascular conditions & $6(22.2)$ & $3(18.8)$ & 0.780 \\
\hline CNS conditions & $8(29.6)$ & $1(6.3)$ & 0.069 \\
\hline GIT conditions & $3(11.1)$ & 0 & - \\
\hline Renal conditions & $2(7.4)$ & 0 & - \\
\hline \multicolumn{4}{|l|}{ Infections } \\
\hline Bacterial sepsis & $6(22.2)$ & $4(25)$ & 0.660 \\
\hline Viral infection & $5(18.5)$ & $1(0.06)$ & 0.390 \\
\hline
\end{tabular}

It was clear that bacterial pneumonia and PCP pneumonia were the predominant LRTIs affecting HIV-exposed children. Kitchin $^{[11]}$ suggested that the immune dysregulation that increases the risk for PCP in HIV-infected children is also present in HIV-exposed but uninfected children.

\section{Comparison between HIV PCR- positive and PCR-negative children} HIV-infected children had a higher mortality compared with those who were exposed but uninfected, but this difference was not statistically significant. HIV-infected children had a significantly longer duration of ICU stay and duration of ventilation than exposed but uninfected patients. This finding is similar to that in other studies in which it was found that HIV-infected children had a longer length of hospital stay because of the increased severity of their LRTI. [20,21] $^{2}$

A study done at the Steve Biko Academic Hospital PICU showed better survival to 1 year of age compared with previous studies when HAART was initiated early in the course of the disease. ${ }^{[1]]}$ This highlights the importance of early testing and initiation of ARVs for children, as well as an effective prevention of mother-to-child transmission programme in decreasing the burden of HIV.

It has been said that PCP occurs most frequently in HIV-infected children, and can be the first clinical presentation of HIV infection. ${ }^{[22]}$ We found 7 HIVinfected children clinically diagnosed with PCP compared with 3 HIV-exposed but uninfected children $(p=0.14)$. Only 2 children were proven sputum-positive for PCP in this group; however, this is not a sensitive method of diagnosis, even though microscopic visualisation is the gold standard. ${ }^{[23]}$

\section{Study limitations}

This was a retrospective study. Different clinicians may have used different criteria for the clinical diagnosis of some conditions. Some data were missing and there was no routine screening of patients for respiratory pathogens. It is difficult to know whether some of the positive cultures were contaminants. The exclusion of all neonates may have led to those with medical, and not purely neonatal conditions, being missed.

\section{Conclusion}

The PICU admitted slightly fewer than 900 children in 19 months. The mortality rate of the children with medical conditions was $24.4 \%$. The most frequent cause for admission was LRTI, which is reflective of the high rates of pneumonia affecting SA children. Overall, 34\% of children were HIV-exposed while $12.2 \%$ were HIV PCR-positive. These children were mostly admitted for LRTIs with bacterial pneumonia and PCP being prominent causes.

Although the HIV-exposed patients were more seriously ill, as proven by increased need for HFOV and longer duration of ventilation and PICU stay, they did not have a higher mortality. Their exclusion from admission to the PICU is no longer justified, especially in the era of HAART.

\section{References}

1. South Africa's Children: A review of equity and child rights. South African Human Rights Commission/UNICEF, March 2011, Pretoria, SA.

2. World Health Organization. Global Health Observatory Data. 2015. http://www.who.int/ gho/child health/mortality/causes/en (accessed 2 August 2016).

3. Bhagwanjee S, Scribante J. National audit of critical care resources in South Africa - unit and bed distribution. S Afr Med J 2007;97(12 Pt 3):1311-1314.

4. Argent AC, Ahrens J, Morrow BM, et al. Pediatric intensive care in South Africa: An account of making optimum use of limited resources at the Red Cross War Memorial Children's Hospital. Pediatr Crit Care Med 2014;15(1):7-14. http:// dx.doi.org/10.1097/PCC.0000000000000029

5. Rabie H, de Boer A, van den Bos S, Cotton MF, Kling S, Goussard P. Children with human immunodeficiency virus infection admitted to a paediatric intensive care unit in South Africa. J Trop Pediatr 2007;53(4):270-273. http://dx.doi. org/10.1093/tropej/fmm036

6. Rady HI, Mohamed SA, Mohssen NA, ElBaz M. Application of different scoring systems and their value in pediatric intensive care. Gaz Egypt Pediatr Assoc 2014;62(3):59-64. http://dx.doi. org/10.1016/j.epag.2014.10.003

7. Wells M, Riera-Fanego JF, Luyt DK, Dance $M$, Lipman J. Poor discriminatory performance of the pediatric risk of mortality (PRISM) score in a South African intensive care unit. Crit Care Med 1996;24(9):1507-1513. http://dx.doi. org/10.1097/00003246-199609000-00013

8. Solomon LJ, Morrow BM, Argent AC. Paediatric index of mortality scores: An evaluation of function in the paediatric intensive care unit of the Red Cross War Memorial Children's Hospital. S Afr J Crit Care 2014;30(1):8-13. http://dx.doi. org/10.7196/sajcc.166

9. Ballot DE, Davies VA, Rothberg AD, Ginsberg N. Selection of paediatric patients for intensive care. S Afr Med J 1995;85(11 Suppl):1221-1223, 1226.

10. Joint United Nations Programme on HIV and AIDS. HIV and AIDS Estimates 2014. http:// www.unaids.org/en/regionscountries/countries/ southafrica (accessed 24 March 2016).

11. Kitchin OP, Masekela R, Becker P, Moodley T, Risenga SM, Green RJ. Outcome of human immunodeficiency virus-exposed and -infected children admitted to a pediatric intensive care unit for respiratory failure. Pediatr Crit Care Med 2012;13(5):516-519. http://dx.doi.org/10.1097/ pcc.0b013e31824ea143 
12. Jeena PM, McNally LM, Stobie M, Coovadia HM, Adhikari MA, Petros AJ. Challenges in the provision of ICU services to HIV-infected children in resource poor settings: A South African case study. J Med Ethics 2005;31(4):226-230. http://dx.doi.org/10.1136/jme.2003.004010

13. Kitchin OP, Wessels F, Masekela R, Becker P, Green RJ. Costs of admission for paediatric pneumonia in a setting of human immunodeficiency virus infection. Int J Tuberc Lung Dis 2011;15(12):1702-1707. http://dx.doi.org/10.5588/ijtld.11.0167

14. Slyker JA, Lohman-Payne BL, John-Stewart GC, et al. Acute cytomegalovirus infection in Kenyan HIV-infected infants. AIDS 2009;23(16):2173-2181. http:// dx.doi.org/10.1097/QAD.0b013e32833016e8

15. Harris PA, Taylor R, Thielke R, Payne J, Gonzalez N, Conde JG. Research electronic data capture (REDCap) - A metadata-driven methodology and workflow process for providing translational research informatics support. J Biomed Inform 2009;42(2):377-381. http://dx.doi.org/10.1016/j. jbi.2008.08.010

16. Haque A, Bano S. Clinical profile and outcome in a paediatric intensive care unit in Pakistan. J Coll Physicians Surg Pak 2009;19(8):534-535. http://dx.doi. org/08.2009/JCPSP.534535

17. Zar HJ, Jeena P, Argent A, Gie R, et al. Diagnosis and management of community-acquired pneumonia in childhood - South African Thoracic Society guidelines. S Afr Med J 2005;95(12 Pt 2):977-981,984-990.

18. Green RJ, Zar HJ, Jeena PM, Madhi SA, Lewis H. South African guideline for the diagnosis, management and prevention of acute viral bronchiolitis in children. $S$ Afr Med J 2010;100(5):320,322-325. http://dx.doi.org/10.7196/samj.4016
19. Le Roux DM, Myer L, Nicol MP, Zar HJ. Incidence and severity of childhood pneumonia in the first year of life in a South African birth cohort: The Drakenstein Child Health Study. Lancet 2015;3(2):95-103. http://dx.doi. org/10.1016/S2214-109X(14)70360-2

20. Zar HJ, Hanslo D, Tannenbaum E, et al. Aetiology and outcome of pneumonia in human immunodeficiency virus-infected children hospitalized in South Africa. Acta Paediatr 2001;90(2):119-125. http://dx.doi. org/10.1080/080352501300049163

21. Cohen C, Walaza S, Moyes J, et al. Epidemiology of viral-associated acute lower respiratory tract infection among children $<5$ years of age in a high HIV prevalence setting, South Africa, 2009 - 2012. Pediatr Infect Dis J 2015;34(1):6672. http://dx.doi.org/10.1097/INF.0000000000000478

22. Zar HJ. Pneumonia in HIV-infected and HIV-uninfected children in developing countries: Epidemiology, clinical features, and management. Curr Opin Pulm Med 2004;10(3):176-182. http://dx.doi.org/10.1097/00063198-20040500000006

23. Onishi A, Sugiyama D, Kogata Y, et al. Diagnostic accuracy of serum 1,3-betaD-glucan for Pneumocystis jiroveci (sic) pneumonia, invasive candidiasis, and invasive aspergillosis: Systematic review and meta-analysis. J Clin Microbiol 2012;50(1):7-15. http://dx.doi.org/10.1128/JCM.05267-11

Accepted 29 August 2016 